\title{
(6) OPEN ACCESS \\ A first-in-human clinical study of a new SP-B and SP-C enriched synthetic surfactant (CHF5633) in preterm babies with respiratory distress syndrome
}

\author{
David G Sweet, ${ }^{1}$ Mark A Turner, ${ }^{2}$ Zbyněk Straňák, ${ }^{3}$ Richard Plavka, ${ }^{4}$ Paul Clarke, ${ }^{5}$ \\ Ben J Stenson, ${ }^{6}$ Dominique Singer, ${ }^{7}$ Rangmar Goelz, ${ }^{8}$ Laura Fabbri, ${ }^{9}$ Guido Varoli, ${ }^{9}$ \\ Annalisa Piccinno, ${ }^{9}$ Debora Santoro, ${ }^{9}$ Christian P Speer $^{10}$
}

For numbered affiliations see end of article.

\section{Correspondence to}

Dr David G Sweet, Neonatal Unit, Royal Maternity Hospital, Grosvenor Road, Belfast, BT12 6BB, Northern Ireland, UK ; david.sweet@belfasttrust. hscni.net

Received 16 January 2017 Revised 7 March 2017 Accepted 9 March 2017 Published Online First 2 May 2017
CrossMark

To cite: Sweet DG, Turner MA, Straňák Z, et al. Arch Dis Child Fetal Neonatal Ed 2017;102:F497-F503.

\begin{abstract}
Objective CHF5633 (Chiesi Farmaceutici S.p.A., Parma, Italy) is the first fully synthetic surfactant enriched by peptide analogues of two human surfactant proteins. We planned to assess safety and tolerability of CHF5633 and explore preliminary efficacy.

Design Multicentre cohort study.

Patients Forty infants from $27^{+0}$ to $33^{+6}$ weeks gestation with respiratory distress syndrome requiring fraction of inspired oxygen $\left(\mathrm{FiO}_{2}\right) \geq 0.35$ were treated with a single dose of CHF5633 within 48 hours after birth. The first 20 received $100 \mathrm{mg} / \mathrm{kg}$ and the second 20 received $200 \mathrm{mg} / \mathrm{kg}$.
\end{abstract}

Outcome measures Adverse events (AEs) and adverse drug reactions (ADRs) were monitored with complications of prematurity considered AEs if occurring after dosing. Systemic absorption and immunogenicity were assessed. Efficacy was assessed by change in $\mathrm{FiO}_{2}$ after dosing and need for poractant-alfa rescue.

Results Rapid and sustained improvements in $\mathrm{FiO}_{2}$ were observed in 39 (98\%) infants. One responded neither to CHF5633 nor two poractant-alfa doses. A total of 79 AEs were experienced by 19 infants in the $100 \mathrm{mg} /$ $\mathrm{kg}$ cohort and 53 AEs by 20 infants in the $200 \mathrm{mg} /$ $\mathrm{kg}$ cohort. Most AEs were expected complications of prematurity. Two unrelated serious AEs occurred in the second cohort. One infant died of necrotising enterocolitis and another developed viral bronchiolitis after discharge. The single ADR was an episode of transient endotracheal tube obstruction following a $200 \mathrm{mg} / \mathrm{kg}$ dose. Neither systemic absorption, nor antibody development to either peptide was detected. Conclusions Both CHF5633 doses were well tolerated and showed promising clinical efficacy profile. These encouraging data provide a basis for ongoing randomised controlled trials.

Trial registration number ClinicalTrials.gov NCT01651637.

\section{INTRODUCTION}

Respiratory distress syndrome (RDS) remains a leading cause of morbidity in preterm babies. ${ }^{1}$ Surfactant replacement therapy has become standard of care in RDS management. ${ }^{23}$ Comparative trials show superiority of natural, animal-derived surfactants over protein-free synthetic surfactants due to the presence of surfactant proteins SP-B and SP-C. ${ }^{4} \mathrm{~A}$ fully synthetic surfactant would have

\section{What is already known on this topic?}

Randomised trials have confirmed superiority of natural, animal-derived surfactants containing proteins, over synthetic surfactants comprised of phospholipids alone.

- New generation surfactants that contain peptides mimicking effects of surfactant proteins have shown promise but are not yet widely accepted.

\section{What this study adds?}

- This first-in-human trial of synthetic surfactant CHF5633, containing peptide analogues of two surfactant proteins, shows that it was well tolerated without unexpected adverse effects.

- CHF5633 is similar in volume and appearance to poractant-alfa and appears to work as effectively.

potential advantages such as no dependence on animal sources and less batch-to-batch variability. ${ }^{5}$ Animal experiments suggest that synthetic surfactants containing both peptides are superior to single peptide surfactants. ${ }^{6}$

CHF5633 is a new fully synthetic surfactant preparation consisting of phosphatidylcholine and phosphatidylglycerol, enriched by peptide analogues of both human surfactant proteins SP-B and SP-C. When suspended in saline the final phospholipid concentration is identical to that of poractant-alfa (Curosurf, Chiesi Farmaceutici S. p. A., Parma, Italy), at $80 \mathrm{mg} / \mathrm{mL}$ and a similar small dosing volume can be used. Intratracheal administration of CHF5633 to preterm newborn rabbits resulted in marked improvement in lung expansion which is no different from poractant-alfa. ${ }^{7}$ The structure of the peptide analogues has been modified to be resistant to oxidative injury and may improve resistance to inactivation. ${ }^{8}{ }^{9}$ Preterm lambs with RDS treated with CHF5633 have better lung and brain injury scores than those treated with poractant-alfa. ${ }^{10}$ Based on these results it was anticipated that CHF5633 would be at least as effective as natural surfactants in the treatment of babies with RDS. 
Surfactant treatment is normally administered as an endotracheal fluid bolus to infants. Conducting a phase I study in adults was not appropriate. Accordingly, following consultation with regulatory agencies and ethics committees, the study was designed to recruit premature neonates with 'mild to moderate' RDS who would be less likely to have other comorbidities and who would respond readily to rescue with other surfactants, if required.

This study aimed to investigate the safety and tolerability of intratracheal administration of CHF5633 in preterm babies. Two different doses $(100 \mathrm{mg} / \mathrm{kg}$ and $200 \mathrm{mg} / \mathrm{kg})$ were evaluated in terms of adverse events (AEs), adverse drug reactions (ADRs), haematology and biochemistry values, incidence of comorbidities, extent of systemic exposure to protein analogues and any potential immune response. Effects of CHF5633 on oxygenation, ventilatory requirements and need for rescue surfactant was assessed to explore efficacy.

\section{METHODS}

This was a first-in-human, single-escalating dose per-cohort study on administration of CHF5633. The trial was conducted in compliance with the Declaration of Helsinki and current guidelines for Good Clinical Practice after approval by regulatory authorities in each participating country and the ethical review boards for each institution and prior registration (ClinicalTrials. gov NCT01651637). Written consent was sought before birth, or soon after, giving parents the maximum time to make an informed decision before enrolment.

Infants were eligible within 48 hours after birth if born between $27^{+0}$ and $33^{+6}$ weeks' gestation, having clinical and radiological findings of RDS, and needing fraction of inspired oxygen concentration $\left(\mathrm{FiO}_{2}\right) \geq 0.35$ on continuous positive airways pressure (CPAP) to maintain preductal pulse oximeter oxygen saturation $\left(\mathrm{SpO}_{2}\right)$ in the range $90 \%-95 \%$. They required a normal cranial ultrasound scan and their clinician considered that surfactant was indicated. Infants were ineligible if they had already received surfactant, were already in another study, had a major congenital malformation, if there was a history of maternal drug/alcohol abuse, a clinical suspicion of pneumonia or sepsis, a 5 min Apgar score $\leq 3$, a history of ruptured membranes of $\geq 3$ weeks, or if seizures or pneumothoraces were detected before enrolment. The study was unusual in recruiting infants from whom, albeit for one dose, usual treatment was withheld. It was anticipated that a single-centre study would be prohibitively slow; therefore 40 babies were enrolled from 12 centres in three European countries, with careful coordination to control recruitment. The first infant was treated on 3 October 2012 and the last completed follow-up on 23 January 2015.

Two groups of 20 infants were treated. The first cohort was given $100 \mathrm{mg} / \mathrm{kg}$ of CHF5633 $(1.25 \mathrm{~mL} / \mathrm{kg})$ and the second cohort $200 \mathrm{mg} / \mathrm{kg}(2.5 \mathrm{~mL} / \mathrm{kg})$, administered by bolus via an endotracheal tube with a short period of manual/mechanical ventilation. No infant could receive more than one dose of $\mathrm{CH} 5633$. Failure of response was defined as fall in $\mathrm{FiO}_{2}$ $<0.10$ to maintain $\mathrm{SpO}_{2} 90 \%-95 \%$ within an hour after treatment. Treatment failures were rescued with either $100 \mathrm{mg} / \mathrm{kg}$ or $200 \mathrm{mg} / \mathrm{kg}$ poractant-alfa (Curosurf, Chiesi Farmaceutici, Parma, Italy). All infants could receive further doses of poractant-alfa as necessary. Decisions around premedication for intubation, positioning for surfactant administration, modes and duration of ventilatory support as well as weaning protocols were left to individual participating centres.

\section{Safety and tolerability}

A Safety Monitoring Board (SMB) was established comprising the principal investigator from each site and an independent neonatologist. The SMB reviewed the safety profile of CHF5633 in the week following administration and provided authorisation to continue. The first four babies in each cohort were recruited individually and recruitment stopped until progress to 7 days was reviewed. The subsequent 16 babies in each cohort were recruited in groups of four before SMB review. Safety and efficacy assessments were performed in the 24 hours following CHF5 633 administration (at 0.5 hour, 1 hours, 3 hours, 6 hours, 12 hours and 24 hours), in the following 6 days (at days 2, 3 and 7) and in the follow-up period (at days 10 and 28, and at 36 weeks' postmenstrual age). $\mathrm{FiO}_{2}, \mathrm{SpO}_{2}$, ventilator settings and blood pressure were monitored. Haematological and biochemical indices were collected at baseline, 24 hours and between 5 days and 10 days postdose. Data on all predefined expected neonatal comorbidities and deviations from expected normal values in haematological/biochemical indices were recorded as AEs and reviewed by the SMB for expectedness, severity and potential relatedness to study medication.

\section{Evidence of systemic absorption and immunogenicity}

Blood concentrations of SP-B and SP-C analogues were measured before, and 3 hours and 24 hours post-treatment using dried blood spots. SP-C concentrations were determined using validated HPLC-MS/MS methods (Accelera, Milan, Italy). Immunogenicity was assessed using $1 \mathrm{~mL}$ blood obtained 4-12 weeks after CHF5633 administration. IgG antibodies to peptides were assayed by titration versus positive control (SGS Life Science Services, Wavre, Belgium).

\section{Efficacy}

Efficacy was evaluated by examining response to CHF5633 in terms of changes in $\mathrm{SpO}_{2}, \mathrm{FiO}_{2}$, mean airway pressure (MAP), peak inspiratory pressure if ventilated and positive end-expiratory pressure at specified time points. Duration of mechanical ventilation was defined as time until first extubation lasting $>24$ hours. Durations of CPAP and supplemental oxygen were recorded. Bronchopulmonary dysplasia (BPD) was defined as need for supplemental oxygen to maintain $\mathrm{SpO}_{2} \geq 90 \%$ at 36 weeks' postmenstrual age. The number of non-responders requiring rescue surfactant was recorded.

\section{Statistical analysis}

Because of the exploratory nature of this study, no formal power calculation was performed. Twenty babies in each cohort were deemed sufficient for reaching useful preliminary conclusions. Categorical variables are described using summary statistics, frequency count and percentages. Continuous variables are summarised using mean, $\mathrm{SD}$, or median, IQR as appropriate.

\section{RESULTS}

A total of 75 babies were consented and 40 were dosed between October 2012 and November 2014 (figure 1). Baseline demographic data are shown in table 1. Date of patient recruitment, centre, AEs, and outcomes for each participating infant are shown in table 2 .

Treatment with either dose of CHF5633 resulted in a rapid improvement in oxygenation with corresponding decrease in the need for supplemental oxygen and a reduced MAP (figure 2). Ten babies were extubated to CPAP immediately following CHF5633 administration and never ventilated. A 


\section{5 consented neonates}

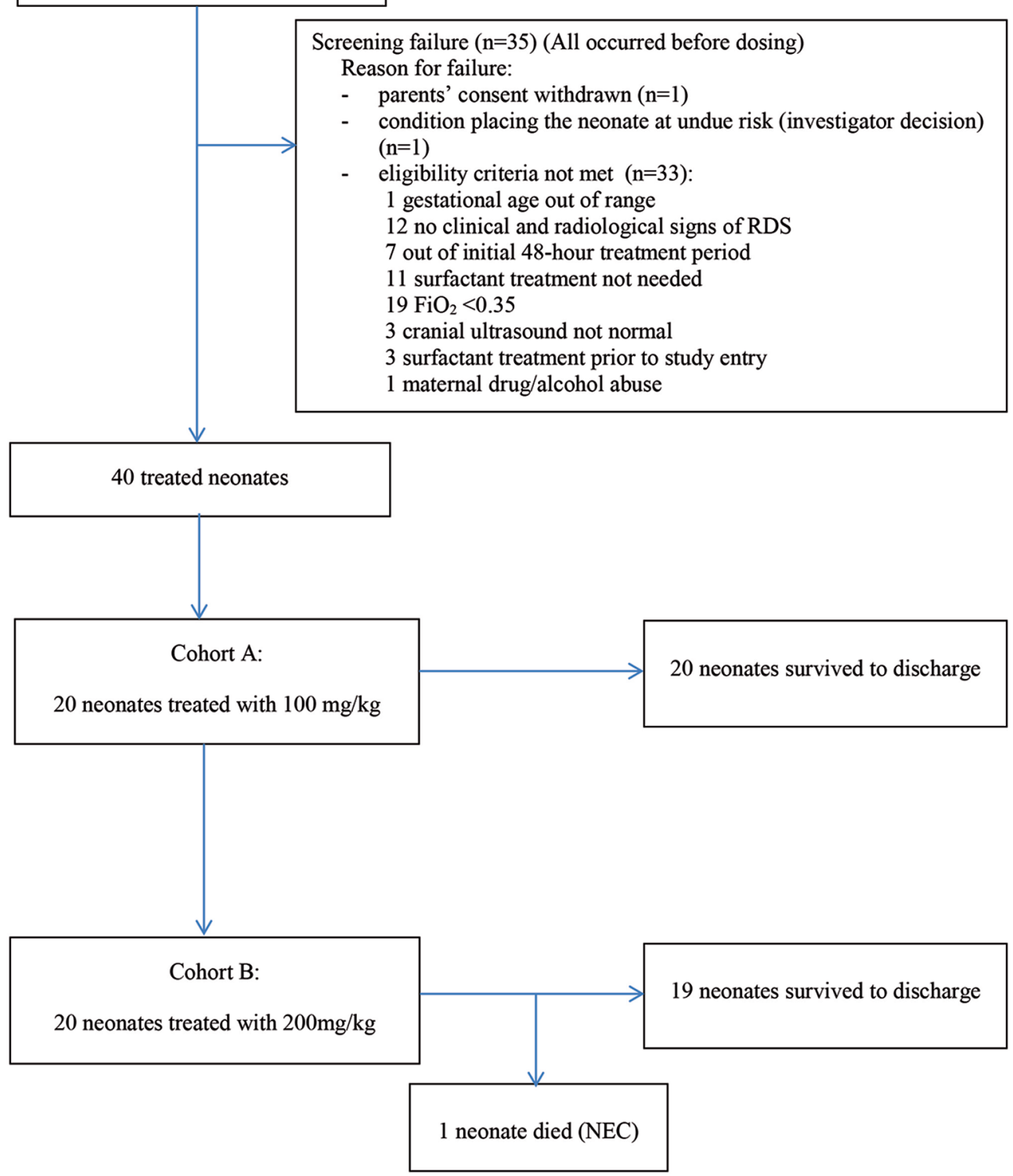

Figure 1 Patients' disposition. FiO ${ }_{2}$, fraction of inspired oxygen; NEC, necrotising enterocolitis; RDS, respiratory distress syndrome.

\begin{tabular}{lcc}
\hline Table 1 & Baseline characteristics & \\
\hline & $\begin{array}{l}100 \mathbf{m g} / \mathbf{k g} \text { cohort } \\
(\mathbf{n}=20)\end{array}$ & $\begin{array}{l}200 \mathrm{mg} / \mathbf{k g} \text { cohort } \\
(\mathbf{n}=20)\end{array}$ \\
\hline Gestational age (weeks) & $29.6(2.0)$ & $29.6(1.9)$ \\
\hline Birth weight (g) & $1274(398)$ & $1364(416)$ \\
5 min Apgar & $8.5(8-9.5)$ & $8(7-8.5)$ \\
Gender male & $11(55 \%)$ & $10(50 \%)$ \\
Antenatal steroids & $18(90 \%)$ & $19(95 \%)$ \\
Antenatal antibiotics & $11(55 \%)$ & $9(45 \%)$ \\
FiO ${ }_{2}$ predose & $0.47(0.16)$ & $0.52(0.13)$ \\
\hline Time to treatment (hours) & $7(4-23)$ & $5(3-16.5)$ \\
\hline
\end{tabular}

was $14.4(4.9-29.9)$ days in the $100 \mathrm{mg} / \mathrm{kg}$ cohort and 6.7 (4.0-14.1) in the $200 \mathrm{mg} / \mathrm{kg}$ cohort. There was only one case of failure to respond to CHF5633, in the first cohort. This 32 -week gestation $1490 \mathrm{~g}$ baby was treated at 37 hours of age, and had two further $200 \mathrm{mg} / \mathrm{kg}$ doses of poractant-alfa, but still without improvement in oxygenation. A pneumothorax was diagnosed 5 hours after study treatment; this was drained and the infant responded to high-frequency oscillation. In 2 of the 40 infants a repeat dose of poractant-alfa was required as part of ongoing management (table 2). Four babies developed $\mathrm{BPD}$, two from each dosing cohort.

Data are shown as mean (SD) and $\mathrm{n}(\%)$,

Median (IQR) is reported for Apgar score and time to treatment.

$\mathrm{FiO}_{2}$, fraction of inspired oxygen.

further four were ventilated for $<30 \mathrm{~min}$. The median (IQR) duration of mechanical ventilation was $0.70 \quad(0.30-0.91)$ days in the $100 \mathrm{mg} / \mathrm{kg}$ cohort and $0.30(0.02-0.95)$ days in the $200 \mathrm{mg} / \mathrm{kg}$ cohort. The median (range) duration of CPAP

\section{Systemic absorption/immunogenicity}

No quantifiable concentrations of the SP-C analogue were detected in any blood sample at any time point. It was impossible to assess absorption of the SP-B analogue because in low quantities it is difficult to measure. No immune response antibodies were detected to either peptide from 36 available samples. 


\section{Original article}

Table 2 Patient sequence, individual characteristics, adverse events and outcomes

\begin{tabular}{|c|c|c|c|c|c|c|c|c|c|c|}
\hline Treatment date & Country & $\begin{array}{l}\text { Age } R_{x} \\
\text { (hours) }\end{array}$ & $\mathrm{FiO}_{2}$ & Sex & BW (g) & $\begin{array}{l}\text { GA } \\
\text { (week) }\end{array}$ & $\begin{array}{l}\text { Laboratory } \\
\text { abnormalites }\end{array}$ & Initial MV & CPAP & Adverse events \\
\hline \multicolumn{11}{|l|}{$100 \mathrm{mg} / \mathrm{kg}$ cohort } \\
\hline 3 October 2012 & $\mathrm{UK}^{2}$ & 2 & 0.42 & $M$ & 1505 & 30 & $\downarrow \mathrm{Na} \uparrow \mathrm{SBR}$ & 22 hours & 6 days & \\
\hline 24 January 2013 & $\mathrm{UK}^{2}$ & 24 & 0.57 & M & 1160 & 31 & $\uparrow S B R$ & 5 hours & 5 days & \\
\hline 16 February 2013 & $\mathrm{UK}^{1}$ & 5 & 0.38 & $\mathrm{~F}$ & 900 & 27 & $\downarrow \mathrm{Na} \uparrow \mathrm{WCC}$ & 3 hours & 39 days & \\
\hline 1 March 2013 & $\mathrm{UK}^{1}$ & 4 & 0.70 & M & 1660 & 31 & $\uparrow N a \downarrow K$ & 17 hours & 3 days & \\
\hline 19 April 2013 & $\mathrm{UK}^{1}$ & 4 & 0.40 & $\mathrm{~F}$ & 1010 & 28 & $\downarrow \mathrm{Na}$ & INSURE & 11 days & \\
\hline 26 April 2013 & $\mathrm{UK}^{1}$ & 24 & 0.45 & $\mathrm{~F}$ & 1270 & 30 & None & 21 hours & none & \\
\hline 21 May 2013 & $\mathrm{GER}^{8}$ & 8 & 0.44 & M & 805 & 28 & $\downarrow W C C \uparrow S B R \uparrow B G$ & 18 hours & 47 days & \\
\hline 11 June 2013 & $\mathrm{UK}^{1}$ & 6 & 0.40 & $\mathrm{~F}$ & 1243 & 31 & $\downarrow N a \downarrow K$ & INSURE & 9 days & \\
\hline 27 June 2013 & $\mathrm{GER}^{7}$ & 15 & 0.45 & $\mathrm{~F}$ & 988 & 28 & $\uparrow S B R$ & 1 day & 29 days & PDA \\
\hline 29 June 2013 & $U K^{6}$ & 4 & 0.36 & M & 1100 & 27 & None & 6 hours & 6 days & IVH day 5 PVL day 28. \\
\hline 8 July 2013 & $\mathrm{GER}^{10}$ & 4 & 0.40 & $\mathrm{M}$ & 2250 & 33 & $\uparrow S B R$ & 14 hours & 2 days & \\
\hline 31 July 2013 & $U^{2}$ & 5 & 0.44 & $\mathrm{~F}$ & 1995 & 32 & $\uparrow C R P$ & 17 hours & none & \\
\hline 20 September 2013 & $\mathrm{UK}^{1}$ & 9 & 0.36 & $\mathrm{~F}$ & 832 & 28 & $\downarrow \mathrm{Na}$ & INSURE & 36 days & \\
\hline 22 September 2013 & $\mathrm{GER}^{10}$ & 1 & 0.35 & M & 1490 & 32 & None & 16 hours & 3 days & $\begin{array}{l}\text { Non-responder, PTX rescue } \\
\text { Poractant } \times 2\end{array}$ \\
\hline 18 October 2013 & $\mathrm{GER}^{8}$ & 37 & 0.45 & $\mathrm{~F}$ & 1490 & 33 & $\uparrow H R$ & 4 days & 6 days & SVT day 20 \\
\hline 6 November 2013 & $U^{1}$ & 3 & 0.68 & M & 1140 & 28 & $\downarrow \mathrm{Na}$ & 8 hours & 23 days & PDA \\
\hline 22 November 2013 & $\mathrm{UK}^{1}$ & 41 & 0.40 & M & 843 & 28 & $\downarrow \mathrm{Na} \uparrow \mathrm{SBR}$ & 3 hours & 55 days & \\
\hline 15 December 2013 & $\mathrm{GER}^{7}$ & 24 & 1.0 & M & 1371 & 29 & $\uparrow S B R$ & 21 hours & 19 days & PDA \\
\hline 8 January 2014 & $\mathrm{UK}^{1}$ & 10 & 0.36 & M & 1580 & 31 & $\downarrow$ Na $\uparrow S B R \downarrow$ plats & INSURE & 8 days & \\
\hline 30 January 2014 & $\mathrm{UK}^{5}$ & 22 & 0.36 & $\mathrm{~F}$ & 850 & 27 & None & 10 days & 53 days & PDA second dose Poractant day 5 \\
\hline \multicolumn{11}{|l|}{$200 \mathrm{mg} / \mathrm{kg}$ cohort } \\
\hline 21 February 2014 & $\mathrm{GER}^{7}$ & 2 & 0.50 & $\mathrm{~F}$ & 1050 & 30 & $\uparrow S B R$ & 12 hours & 3 days & Apnoeic episode \\
\hline 23 March 2014 & $\mathrm{CZE}^{3}$ & 4 & 0.80 & M & 1100 & 27 & $\uparrow S B R$ & 10 hours & 48 days & PDA \\
\hline 12 April 2014 & $U K^{6}$ & 4 & 0.75 & M & 1685 & 30 & $\downarrow$ plats & 19 hours & 13 days & \\
\hline 9 May 2014 & $\mathrm{CZE}^{4}$ & 3 & 0.50 & M & 1070 & 28 & $\uparrow S B R$ & INSURE & 4 days & Apnoeic episode \\
\hline 26 May 2014 & $\mathrm{CZE}^{4}$ & 26 & 0.38 & $\mathrm{~F}$ & 1800 & 32 & None & INSURE & 4 days & \\
\hline 27 May 2014 & $\mathrm{CZE}^{4}$ & 20 & 0.38 & $\mathrm{~F}$ & 1075 & 27 & None & INSURE & 16 days & Episode of ET tube blockage, PDA \\
\hline 1 June 2014 & $\mathrm{CZE}^{3}$ & 2 & 0.60 & $\mathrm{~F}$ & 1590 & 30 & $\uparrow S B R$ & INSURE & 5 days & \\
\hline 1 June 2014 & $\mathrm{CZE}^{3}$ & 3 & 0.40 & $\mathrm{~F}$ & 1490 & 30 & $\uparrow S B R$ & INSURE & 4 days & \\
\hline 25 June 2014 & $\mathrm{CZE}^{3}$ & 2 & 0.45 & M & 1130 & 28 & $\uparrow S B R \downarrow N a$ & 40 mins & 26 days & \\
\hline 26 June 2014 & $\mathrm{CZE}^{3}$ & 25 & 0.51 & M & 1060 & 28 & $\uparrow S B R \downarrow N a$ & INSURE & 26 days & \\
\hline 27 June 2014 & $\mathrm{GER}^{10}$ & 5 & 0.60 & M & 975 & 28 & None & 14 hours & 12 days & $\begin{array}{l}\text { PDA, PTX, } \\
\text { second dose Poractant day 2, NEC } \\
\text { day } 13 \text { - died }\end{array}$ \\
\hline 28 July 2014 & UK & 5 & 0.63 & M & 1690 & 33 & None & 20 hours & 1 day & \\
\hline 29 August 2014 & $U K^{5}$ & 5 & 0.55 & $\mathrm{~F}$ & 870 & 27 & None & INSURE & 33 days & \\
\hline 15 Septembert 2014 & $\mathrm{CZE}^{4}$ & 33 & 0.70 & $\mathrm{~F}$ & 2080 & 32 & $\uparrow S B R$ & INSURE & 4 days & \\
\hline 26 September 2014 & $U^{1}$ & 13 & 0.36 & $\mathrm{~F}$ & 876 & 31 & $\uparrow S B R, \downarrow N a$ & INSURE & 8 days & \\
\hline 26 September 2014 & $\mathrm{CZE}^{3}$ & 10 & 0.50 & M & 1306 & 30 & None & 1 hour & 12 days & \\
\hline 21 October 2014 & $\mathrm{CZE}^{3}$ & 2 & 0.55 & M & 1720 & 31 & $\uparrow S B R$ & 1 hour & 7 days & \\
\hline 11 November 2014 & $\mathrm{UK}^{1}$ & 29 & 0.41 & M & 1688 & 30 & None & 23 hours & 7 days & \\
\hline 18 November 2014 & $U^{6}$ & 5 & 0.48 & $\mathrm{~F}$ & 2190 & 32 & None & 5 hours & 2 days & \\
\hline 21 November 2014 & $U^{5}$ & 6 & 0.41 & $\mathrm{~F}$ & 840 & 28 & None & 3 days & 41 days & \\
\hline
\end{tabular}

$\downarrow \mathrm{Na}$, hyponatraemia; $\downarrow K$, hypokalaemia; $\uparrow S B R$, hyperbilirubinaemia; $\uparrow W C C$, leucocytosis; $\downarrow$ WCC, leucopenia; $\uparrow$ BG, hyperglycaemia; $\uparrow C R P$, elevated C reactive protein; $\downarrow$ plats, thrombocytopenia; $\uparrow$ HR, tachycardia; PTX, pneumothorax; IVH, intraventricular haemorrhage; NEC, necrotising enterocolitis; PDA, patent ductus arteriosus; PVL, periventricular leucomalacia; SVT, supraventricular tachycardia; Column 2 shows sequence of recruitment by country and site. GER-Germany; CZE-Czech Republic. Site number according to instutions of authors. Age $\mathrm{R}$, treatment age; $\mathrm{FiO}_{2}$ fraction of inspired oxygen required just prior to dosing; $\mathrm{BW}$, birthweight; $\mathrm{GA}$, gestational age; $\mathrm{MV}$, mechanical ventilation; CPAP, continuous positive airways pressure; ET, endotracheal; INSURE, INtubation-SURfactant_Extubation

Adverse events

In total, 132 AEs were recorded, 79 experienced by 19 (95\%) infants in the $100 \mathrm{mg} / \mathrm{kg}$ cohort and 53 by $20(100 \%)$ infants in the $200 \mathrm{mg} / \mathrm{kg}$ cohort. Most events were expected clinical problems of preterm infants such as mild hyponatraemia. The investigators assessed and classified the laboratory values as normal, abnormal/ not significant or abnormal/clinically significant. Most abnormalities were assessed as abnormal/not significant. Comorbidities before and after treatment are summarised in table 3 and are typical of issues in preterm babies. 

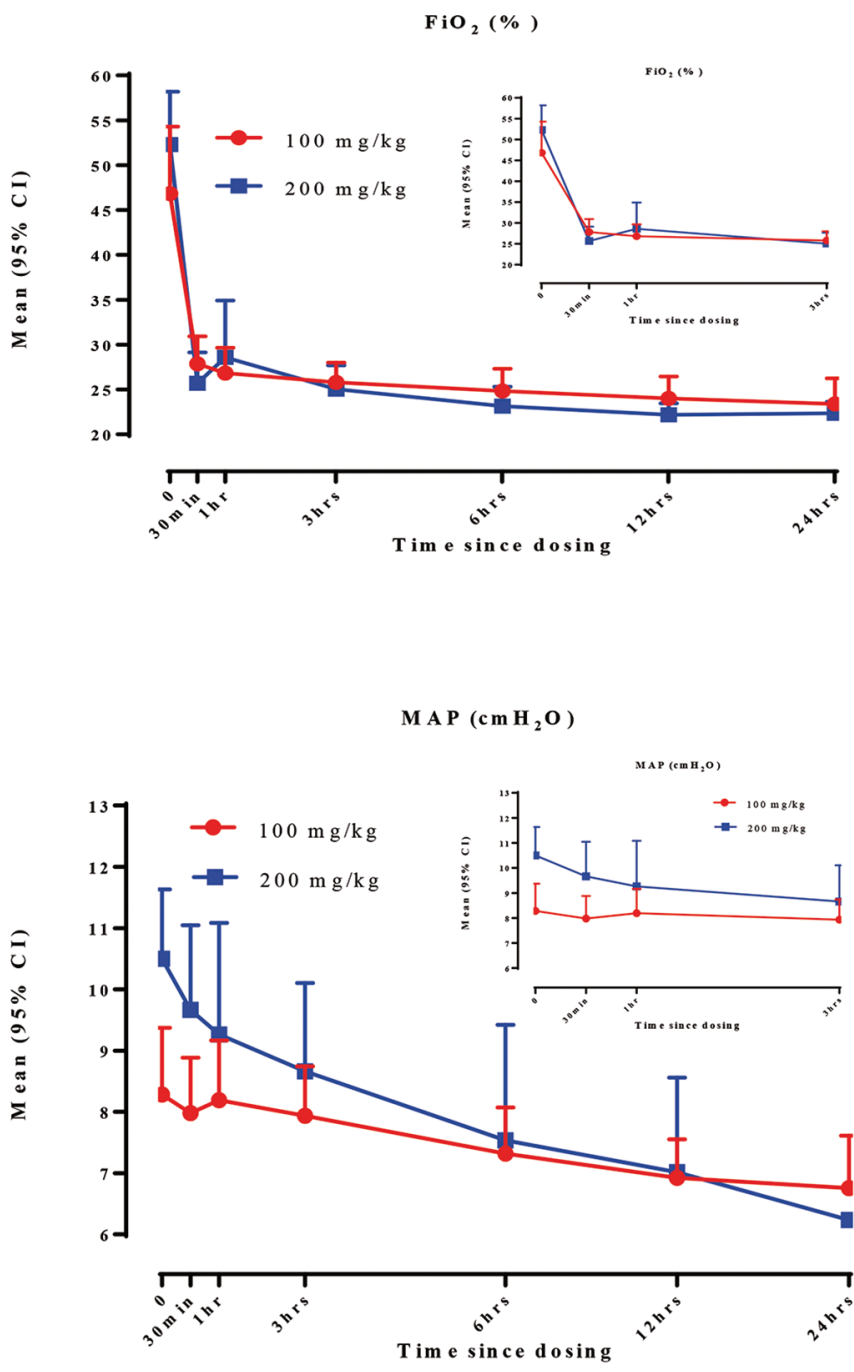

Figure 2 Fraction of inspired oxygen $\left(\mathrm{FiO}_{2}\right)$ in all babies and corresponding mean airway pressure (MAP) in those undergoing mechanical ventilation 24 hours after CHF5633 in the two dosing cohorts. Bars represent SD. Data offset slightly to improve clarity. Inset shows same data over first 3 hours to illustrate speed of onset of action of effect.

\section{Adverse drug reactions}

Only one ADR was reported. Following administration of $200 \mathrm{mg} / \mathrm{kg}$ to a $27^{+2}$ week, $1075 \mathrm{~g}$ infant there was temporary obstruction of the endotracheal tube for 10-15 s, which resolved quickly with no clinical consequences. The baby was extubated after $4 \mathrm{~min}$, with a transient rise in $\mathrm{FiO}_{2}$ to $80 \%$ but reducing over the following 3 hours on CPAP, and had echocardiographic evidence of transient pulmonary hypertension. Neither allergic reactions, nor any other events potentially caused by the drug, were reported.

\section{Serious adverse events}

Two SAEs were reported, both occurring in the $200 \mathrm{mg} /$ kg cohort: an episode of fulminant necrotising enterocolitis occurring 13 days after CHF5633 in an infant of 28 weeks' gestation who died at 21 days, and an episode of postdischarge viral bronchiolitis considered as serious due to need for rehospitalisation. Neither SAE was considered related to the study drug.

\section{DISCUSSION}

This first-in-human study shows that a CHF5633 dose of either $100 \mathrm{mg} / \mathrm{kg}$ or $200 \mathrm{mg} / \mathrm{kg}$ was well tolerated, without detectable systemic absorption, and resulted in prompt and sustained improvements in respiratory function. CHF5633 is the first synthetic surfactant to contain analogues of both SP-B and SP-C. It was developed to be similar to poractant-alfa (Curosurf) in terms of its low dose volume, appearance and simple handling requirements. It requires refrigeration, and only a short period of warming in the hand prior to administration, and the volume to deliver a $200 \mathrm{mg} / \mathrm{kg}$ dose is $2.5 \mathrm{~mL} / \mathrm{kg}$. Following a single intratracheal dose the brisk response allowed rapid extubation, including the use of the INtubation-SURfactant-Extubation (INSURE) approach that is widely used with animal-derived surfactants. ${ }^{11}$ Apart from one patient, all infants showed an immediate clinical response with a single dose.

The population selected for this study was reasonably stable babies with RDS, deliberately chosen because of the relatively low risk of complications to allow an informative safety and tolerability assessment. They required surfactant, but were not so unwell that there was insufficient time to obtain consent and baseline investigations. Most were stable on CPAP, but with increasing oxygen requirements. Such babies are scarce, therefore recruitment at multiple sites was needed to achieve the required study population, even though this would be considered unusual for a phase I trial. The initial requirement to halt after each enrolled subject made recruitment slow.

Despite careful selection of subjects, the majority still developed a range of comorbidities that needed to be analysed within the context of what would normally be expected in a preterm baby requiring surfactant. Only one death occurred; a case of NEC considered a consequence of prematurity and unrelated to CHF5633 treatment. The single episode of transient tube obstruction was also considered a well recognised complication of surfactant therapy. Neither allergic reactions nor other events likely caused by the drug were reported. Lack of systemic exposure and of specific immune response was also reassuring. The overall rate of mortality, BPD, and their combination was low as would be expected with this selected, relatively low-risk, preterm population. ${ }^{12}$ These data are promising and randomised controlled trials should now determine how CHF5633 performs in a larger population including less mature and sicker infants (ClinTrials.gov NCT02452476).

Baseline characteristics were similar in the two dosing cohorts, although the predose $\mathrm{FiO}_{2}$ and MAP were slightly higher in the second cohort, perhaps reflecting increasing confidence at recruiting sicker babies. Statistical comparisons were not made between dosing cohorts for this reason. Both doses were efficacious, resulting in sustained improvements in oxygenation that occurred immediately after instillation. A median $\mathrm{FiO}_{2}$ of 0.21 was achieved within the first 24 hours of treatment. In terms of respiratory support, a shorter duration of non-invasive ventilation was found in the $200 \mathrm{mg} / \mathrm{kg}$ cohort despite them being slightly worse at baseline. This might reflect a greater improvement of lung mechanics with higher doses of CHF5633, although this needs to be tested in randomised trials.

Only one other protein-containing synthetic surfactant, lucinactant, had reached the stage of being used in comparative clinical trials in preterm neonates. ${ }^{13} 14$ Lucinactant contains a high concentration of the synthetic peptide sinapultide (KL-4), designed to have similar activity to SP-B, but no SP-C peptide. Lucinactant is a viscous fluid requiring warming to $44^{\circ} \mathrm{C}$ then vigorous shaking until it becomes a free-flowing suspension. 
Original article

Table 3 Comorbidities and complications of prematurity

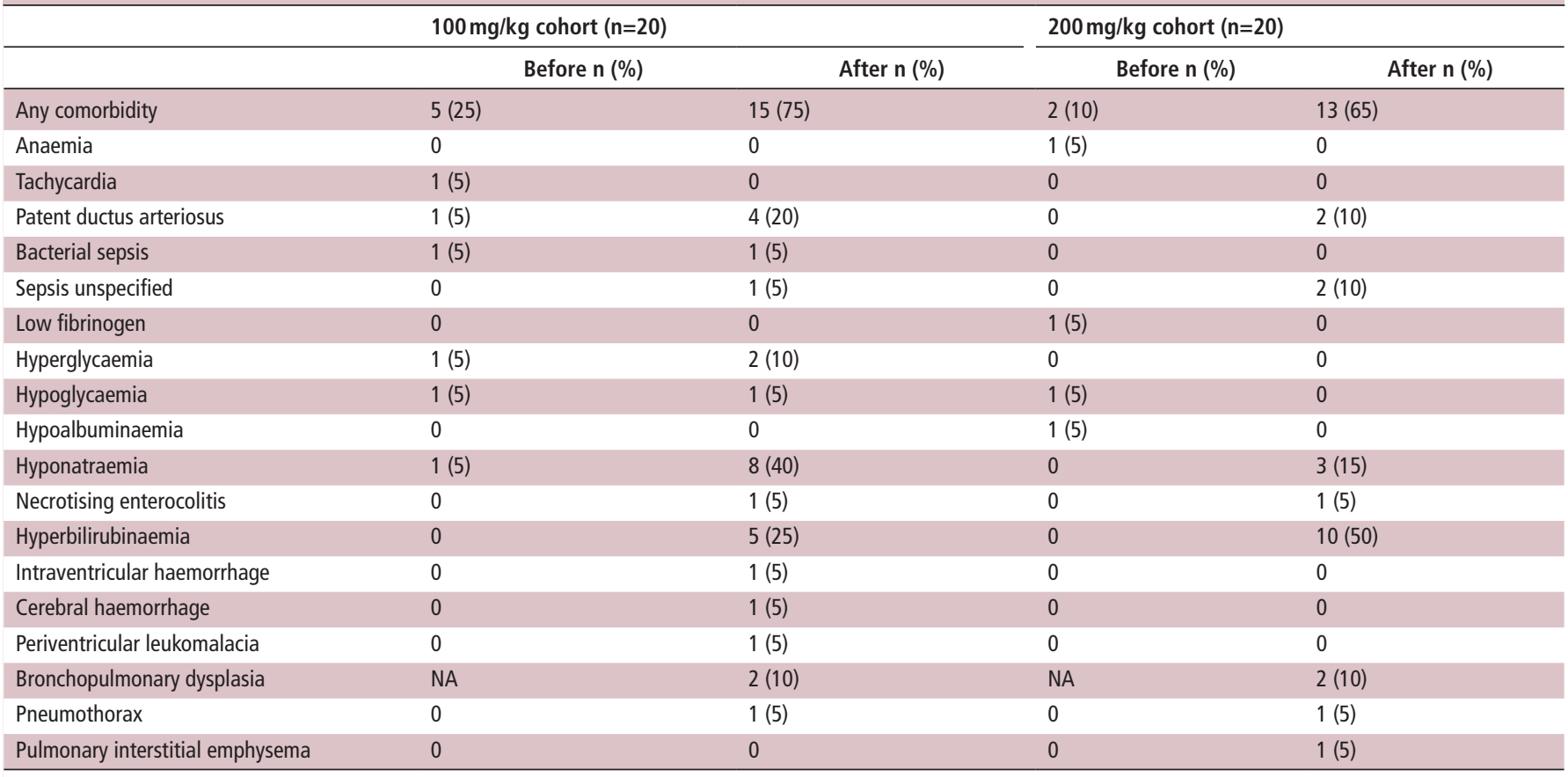

NA, not applicable.

The approved treatment dose volume is $5.8 \mathrm{~mL} / \mathrm{kg}$. In contrast, CHF5633 is more akin to poractant-alfa in terms of its handling requirements and the observed clinical response parallels that observed in trials of existing animal-derived surfactants. ${ }^{15} 16$

Current thinking about optimal management of RDS is to aim where possible to avoid mechanical ventilation. ${ }^{17}$ Administering surfactant without mechanical ventilation is gaining acceptance as a strategy to minimise lung injury. ${ }^{18} 19$ Fourteen babies in this study were extubated within 30 min of CHF5633 administration, including 10 where clinicians employed the INSURE technique. Future comparative trials of CHF5633 should therefore explore all potential modes of administration including minimally invasive methods.

Animal-derived surfactants require pooling of material from multiple animals. Quality control is stringent, but many stakeholders would be reassured if the theoretical risks of infection could be avoided. There is a drive towards ensuring that children of all ages have access to age-appropriate formulations. This involves tailoring administration to the needs of the child and optimising pharmaceutical quality of the product. By ensuring that the volume to be administered is small and avoiding use of animal products, the development of CHF5633 addresses these needs. Ideally it would also prove to be more efficacious in some circumstances. Studies in a sheep model of acute lung injury suggest that CHF5633 may be more resistant to inactivation than poractant-alfa. ${ }^{20}$ This raises the possibility that it may have advantages in severe disease, or in other causes of respiratory failure associated with surfactant inhibition. ${ }^{21-24}$

In conclusion, CHF5633 is the first synthetic surfactant to contain analogues to both surfactant proteins, SP-B and SP-C. This first-in-human study shows that it was well tolerated by preterm babies with moderate RDS and raised no safety concerns, with a promising clinical efficacy profile. Larger trials are warranted and if these produce similar results it is likely that this will herald a new era of synthetic surfactant treatment.

\section{Author affiliations}

${ }^{1}$ Neonatal Unit, Royal Maternity Hospital, Belfast, Northern Ireland, UK
${ }^{2}$ Department of Women's and Children's Health, Institute of Translational Medicine, University of Liverpool, Liverpool, England, UK

${ }^{3}$ Department of Neonatology, Institute for the Care of Mother and Child, Prague, Czech Republic

${ }^{4}$ Division of Neonatology, General Faculty Hospital and 1st Faculty of Medicine, Prague, Czech Republic

${ }^{5}$ Neonatal Intensive Care Unit, Norfolk and Norwich University Hospitals NHS Foundation Trust, Norwich, UK

${ }^{6}$ Neonatal Unit, Simpson Centre for Reproductive Health, Royal Infirmary of Edinburgh, Edinburgh, Scotland, UK

${ }^{7}$ Division of Neonatology and Paediatric Intensive Care, University Medical Center Hamburg-Eppendorf, Hamburg, Germany

${ }^{8}$ Department of Neonatology, University Children's Hospital, Tuebingen, Germany ${ }^{9} \mathrm{Global}$ Clinical Development, Chiesi Farmaceutici S.p.A, Parma, Italy

${ }^{10}$ University Children's Hospital, University of Würzburg, Würzburg, Germany

Acknowledgements The authors thank the following investigators for their help in recruiting and managing study patients: Samir Gupta (University of Durham \& North Tees University Hospital, Stockton-on-Tees, UK), Suzanne Schmidtke (Asklepios Klinik Barmbek, Abteilung Neonatologie, Hamburg, Germany), Sundeep Harigopal (Neonatal Intensive Care Unit, Royal Victoria Infirmary, Newcastle uponTyne, UK), Dr Monika Wolf (Sektion Neonatologie und Pädiatrische Intensivmedizin, Universitätsklinikum Eppendorf, Hamburg), Dr Alison Walker (Neonatal Unit, Royal Maternity Hospital, Belfast), and Dr Rahul Roy (Neonatal Unit, Norfolk and Norwich University Hospital, Norwich, UK). Professor Virgilio Carnielli (Salesi Hospital, Ancona, Italy) served as independent neonatologist on the Safety Monitoring Board. The authors also thank the patients and their families for their participation in the study as well as Chiesi Farmaceutici S.p.A. (Parma, Italy) for the support in conducting this study, and Pharm-Olam International, The Brackens, Ascot (UK) for the periodic monitoring of the clinical sites, data management and statistical analysis.

Contributors DGS recruited patients, was on the safety monitoring board, helped with data analysis, drafted the initial manuscript and approved the final manuscript as submitted. MT recruited patients, helped with manuscript editing and approved the final manuscript and was part of the safety monitoring board. ZS and RP recruited patients and approved the final manuscript. PC recruited patients and helped with manuscript preparation and approved the final manuscript. BS, RG, DSi recruited patients, were on the safety monitoring board, helped with manuscript editing and approved the final manuscript. LF and GV conceptualised and designed the study, assisted with data analysis and approved the final manuscript. AP and DS helped with data presentation and analysis and approved the final manuscript. CPS conceptualised and designed the study, recruited patients, was the chairman of the safety monitoring board, assisted with data analysis and approved the final manuscript. 
Funding Chiesi Farmaceutici S.p.A. (Italy).

Competing interests LF, DS, AP and GV are full employees of Chiesi Farmaceutici S.p.A., sponsor of the study. DGS has previously acted in an advisory capacity for Chiesi Pharmaceuticals UK. CPS is consultant for Chiesi Farmaceutici S.p.A. (Italy). MT serves as a consultant to Chiesi Farmaceutici S.p.A. (Italy) with respect to the development of CHF5633 on behalf of the University of Liverpool without deriving any personal benefit from this consultancy. The remaining authors have no conflict of interest to declare. All authors received clinical research funds from Chiesi Farmaceutici S.p.A. as site investigators for this study.

Ethics approval Ethics review boards for each institution in each country.

Provenance and peer review Not commissioned; externally peer reviewed.

Open Access This is an Open Access article distributed in accordance with the terms of the Creative Commons Attribution (CC BY 4.0) license, which permits others to distribute, remix, adapt and build upon this work, for commercial use, provided the original work is properly cited. See: http://creativecommons.org/licenses/by/4.0/

(c) Article author(s) (or their employer(s) unless otherwise stated in the text of the article) 2017. All rights reserved. No commercial use is permitted unless otherwise expressly granted.

\section{REFERENCES}

1 Stoll BJ, Hansen NI, Bell EF, et al. Eunice Kennedy Shriver National Institute of Child Health and Human Development Neonatal Research Network. Neonatal outcomes of extremely preterm infants from the NICHD neonatal research network. Pediatrics 2010;126:443-56.

2 Curstedt T, Halliday HL, Speer CP. A unique story in neonatal research: the development of a porcine surfactant. Neonatology 2015;107:321-9.

3 Seger N, Soll R. Animal derived surfactant extract for treatment of respiratory distress syndrome. Cochrane Database of Syst Rev 2009;2:CD007836.

4 Ardell S, Pfister RH, Soll R. Animal derived surfactant extract versus protein free synthetic surfactant for the prevention and treatment of respiratory distress syndrome. Cochrane Database of Syst Rev 2015;8:CD000144.

5 Whitsett JA. The molecular era of surfactant biology. Neonatology 2014;105:337-43.

6 Almlén A, Walther FJ, Waring AJ, et al. Synthetic surfactant based on analogues of SP-B and SP-C is superior to single-peptide surfactants in ventilated premature rabbits. Neonatology 2010;98:91-9.

7 Ricci F, Murgia X, Razzetti R, et al. In vitro and in vivo comparison between poractant alfa and the new generation synthetic surfactant CHF5633. Pediatr Res 2017;81:369 75 .

8 Almlén A, Walther FJ, Waring AJ, et al. Synthetic surfactant based on analogues of SP-B and SP-C is superior to single-peptide surfactants in ventilated premature rabbits. Neonatology 2010;98:91-9.

9 Sato A, Ikegami M, Sp-b IM. SP-B and SP-C containing new synthetic surfactant for treatment of extremely immature lamb lung. PLoS One 2012;7:e39392.
10 Rey-Santano C, Mielgo VE, Murgia X, et al. Cerebral and lung effects of a new generation synthetic surfactant with SP-B and SP-C analogs in preterm lambs. Pediatr Pulmonol 2017 Feb 21 [Epub ahead of print]. doi: 10.1002/ppul.23685.

11 Stevens TP, Blennow M, Myers EH, et al. Early surfactant administrationwith brief ventilation versus selective surfactant and continued mechanical ventilation for preterm infants with or at risk for respiratory distress syndrome. Cochrane Database Syst Rev 2007;4:CD003063.

12 Fanaroff AA, Stoll BJ, Wright LL, et al. NICHD Neonatal Research Network. Trends in neonatal morbidity and mortality for very low birthweight infants. Am J Obstet Gynecol 2007;196:147.e1-147.e8.

13 Sinha SK, Lacaze-Masmonteil T, Valls i Soler A, et al. Surfaxin Therapy Against Respiratory Distress Syndrome Collaborative Group. A multicenter, randomized, controlled trial of lucinactant versus poractant alfa among very premature infants at high risk for respiratory distress syndrome. Pediatrics 2005;115:1030-8.

14 Moya FR, Gadzinowski J, Bancalari E, et al. International Surfaxin Collaborative Study Group. A multicenter, randomized, masked, comparison trial of lucinactant, colfosceril palmitate, and beractant for the prevention of respiratory distress syndrome among very preterm infants. Pediatrics 2005;115:1018-29.

15 Bevilacqua G, Halliday H, Parmigiani S, et al. Randomized multicentre trial of treatment with porcine natural surfactant for moderately severe neonatal respiratory distress syndrome. the collaborative european multicentre study group. J Perinat Med 1993:21:329-40.

16 Speer $\mathrm{CP}$, Gefeller $\mathrm{O}$, Groneck $\mathrm{P}$, et al. Randomised clinical trial of two treatment regimens of natural surfactant preparations in neonatal respiratory distress syndrome. Arch Dis Child Fetal Neonatal Ed 1995;72:F8-13.

17 Sweet DG, Carnielli V, Greisen G, et al. European consensus guidelines on the management of respiratory distress syndrome - 2016 update. Neonatology 2017; 111:107-25.

18 Göpel W, Kribs A, Ziegler A, et al. German Neonatal Network. Avoidance of mechanical ventilation by surfactant treatment of spontaneously breathing preterm infants (AMV): an open-label, randomised, controlled trial. Lancet 2011;378:1627-34

19 Kribs A, Roll C, Göpel W, et al. NINSAPP Trial Investigators. Nonintubated surfactant application vs conventional therapy in extremely preterm infants: a randomized clinical trial. JAMA Pediatr 2015;169:723-30.

20 Seehase M, Collins JJ, Kuypers E, et al. New surfactant with SP-B and C analogs gives survival benefit after inactivation in preterm lambs. PLoS One 2012;7:e47631.

21 Salvesen B, Curstedt T, Mollnes TE, et al. Effects of natural versus synthetic surfactant with SP-B and SP-C analogs in a porcine model of meconium aspiration syndrome. Neonatology 2014;105:128-35.

22 Speer CP. Neonatal respiratory distress syndrome: an inflammatory disease? Neonatology 2011;99:316-9.

23 El Shahed Al, Dargaville PA, Ohlsson A, et al. Surfactant for meconium aspiration syndrome in term and late preterm infants. Cochrane Database Syst Rev 2014;12:CD002054.

24 Keiser $A$, Bhandari $\mathrm{V}$. The role of surfactant therapy in nonrespiratory distress syndrome conditions in neonates. Am J Perinatol 2016:33:001-8. 